\section{Factors affecting immunization coverage in urban slums of Odisha, India: implications on urban health policy}

\author{
Santosh K. Prusty, ${ }^{1}$ Bhuputra Panda, ${ }^{2}$ \\ Abhimanyu S. Chauhan, ${ }^{2}$ Jayanta K. Das ${ }^{3}$ \\ 'Department of Health and Family \\ Welfare, Government of Odisha, \\ Bhubaneswar; ${ }^{2}$ Indian Institute of Public \\ Health, Public Health Foundation of \\ India, Bhubaneswar; ${ }^{3}$ National Institute \\ of Health and Family Welfare, New Delhi, \\ India
}

\section{Abstract}

Infectious diseases are major causes of morbidity and mortality among children. One of the most cost-effective interventions for improved child survival is immunization, which has significant urban-rural divides. Slum dwellers constitute about one-third of Indian population, and most children still remain incompletely immunized. The main purpose of this study was to understand the factors behind partial or non-immunization of children aged 12-23 months in slum areas of Cuttack district, India. Session-based audit and a population-based survey were conducted in the urban slums of Cuttack city, April-June 2012. Total 79 children were assessed and their mothers were interviewed about the nature and quality of immunization services provided. Children fully immunized were $64.6 \%$. Antigen-wise immunization coverage was highest for Bacillus Calmette-Guérin (BCG) (96.2\%) and lowest for Measles (65.8\%), which indicates high instances of late drop-out. Frequent illnesses of the child, lack of information about the scheduled date of immunization, frequent displacement of the family and lack of knowledge regarding the benefits of immunization were cited as the main factors behind coverage of immunization services. The study showed that there is an urgent need to revise the immunization strategy, especially for urban slums. District and sub-district officials should reduce instances of early and late dropouts and, in turn, improve complete immunization coverage. Community participation, inter-sectoral co-ordination and local decision making along with supportive supervision could be critical in addressing issues of drop-outs, supply logistics and community mobilization.

\section{Introduction}

Infectious diseases are major causes of morbidity and mortality among children. One of the most cost effective and easy methods for child survival is immunization. Childhood immunization is a proven strategy for prevention of many infectious diseases. ${ }^{1}$ Worldwide, about 2.5 million deaths of under-5 children are averted annually by immunization against diphtheria, tetanus, pertussis, and measles. ${ }^{2}$ In India, vaccine preventable diseases (VPDs) are still responsible for over 0.5 million deaths annually. In May 1974 the World Health Organization (WHO) officially launched a global immunization programme known as Extended Programme of Immunization (EPI) to protect all children against six VPDs by 2000. The EPI was launched in India in January 1978 and subsequently in 1985 was renamed as Universal Immunization Programme (UIP). It covered nine VPDs, namely tuberculosis, diphtheria, whooping cough (pertusis), tetanus, polio, measles, mumps, rubella and hepatitis-B. The National Population Policy (NPP) (2000) highlighted the need for immunizing all children against six common childhood diseases (tuberculosis, tetanus, pertussis, diphtheria, measles and polio). There are wide coverage disparities between the rich and the poor and between urban and rural children. ${ }^{3}$ There is wide interdistrict, intra-district, urban-rural and richpoor difference with respect to immunization coverage. For instance, as compared to the rest of India, the coverage is poor in empowered action group (EAG) states which constitutes more than $40 \%$ of the total population. ${ }^{4}$ Complete immunization coverage in urban areas of Odisha was $49 \%$ as compared to 84 and $73 \%$ in Tamil Nadu and Kerala, respectively. ${ }^{5}$ One of the recent studies indicate that about $60 \%$ children in aged $12-23$ months are fully immunized in Odisha, the same for poor children is a dismal $43 \% .{ }^{6}$ This variation indicates a service coverage gap and reinforces the fact that those who need these services the most are the ones who are also neglected the most. Despite a steady rise in overall immunization coverage, children living in large numbers of slum dwellers remain incompletely immunized. ${ }^{7}$ Government of Odisha defines a slum as a compact settlement of at least 20 households with a collection of poorly built tenements, mostly of temporary nature, crowded together usually with inadequate sanitary and drinking water facilities in unhygienic conditions. ${ }^{8}$ Emerging evidences indicate immunization coverage has been steadily increasing but the average level remains far less than desired. Only $44 \%$ of infants in India are fully immunized - much less than the desired goal of achieving a $85 \%$ coverage. Even though the
Correspondence: Bhuputra Panda, Indian Institute of Public Health, Public Health Foundation of India, E1/1 Infocity Road, 751024 Bhubaneswar, India.

Tel. +91.674.6655601 - Fax: +91.674.6655614.

E-mail: bhuputra.panda@iiphb.org

Key words: vaccination coverage, slum dwellers, factors of immunization, perception of quality, immunization strategy.

Conflict of interests: the authors declare no potential conflict of interests.

Received for publication: 17 May 2013.

Revision received: 12 June 2013.

Accepted for publication: 15 June 2013.

This work is licensed under a Creative Commons Attribution 3.0 License (by-nc 3.0).

(C) Copyright S.K. Prusty et al., 2013

Licensee PAGEPress, Italy

Healthcare in Low-resource Settings 2013; 1:e18 doi:10.4081/hls.2013.e18

coverage in urban areas is relatively better than in rural areas, studies found more than $50 \%$ of poor children are underweight and almost $60 \%$ miss total immunization before completing one year. ${ }^{9}$

We aimed to understand the current status of immunization of children aged 12-23 months and the factors affecting coverage of immunization in a slum set-up. We also studied the perception of mothers about the nature and quality of immunization services provided in the public health system.

\section{Materials and Methods}

\section{Study setting}

Cuttack city, India, has 257 identified urban slums ${ }^{10}$ with a population of about 0.6 million and a density of $4382.23 / \mathrm{km}^{2}$. Male population constitutes about 52 and female $48 \%$. The average literacy rate of the city is $77 \%$ with a remarkable gender difference (male 86 and female 67\%). Cuttack Municipal Corporation (CMC) runs health centres and provides immunization services through the fixed day outreach service delivery approach. As per 2009 slum survey, the city had 223,000 urban slums dwellers. We selected five slum settlements at random, spread across two wards (35 and 36) of the CMC. The total population of all five urban slums together is estimated to be about $5220 .{ }^{11}$

\section{Sampling}

All mothers of children aged 12-23 months residing in the above mentioned five urban 
slums constituted our primary respondents. All children registered in the respective Anganwadi centres (AWC) in the age group of 12 to 23 months were enlisted. Total 79 mothers of children aged 12-23 months were available for the study against expected 105 mothers (calculated with crude birth rate of 20 per 1000 population). Thus, 79 children were assessed for immunization status. On further enquiry, it was found that about 26 eligible mothers had gone to their native places because of summer season and thus were excluded from the study.

\section{Data collection and analysis}

We used session-based audit and population-based survey as the methods for data collection. A semi-structured in-depth interview schedule was developed, field-tested and translated into local language. It contained ten questions in a five point Likert scale pertaining to immunization status, behavior of service providers, waiting time, satisfaction level and economic loss due to immunization, etc. It also contained questions related to studying perception of mothers on factors related to immunizing their children. Data collection was done during April-June 2012. Both quantitative and qualitative techniques were used for data collection. Quantitative analysis was done through SPSS version 16.0. Descriptive statistics was used to show the characteristics of the participants in the study and the extent of coverage against antigens. A bivariate analysis was undertaken for all covariates to identify the factors associated with vaccination coverage. Qualitative data was used for free-listing and content analysis.

\section{Study variables}

We used the WHO guideline for defining full vaccination status. A child who had received one dose of Bacillus CalmetteGuérin (BCG), three doses of oral polio vaccine (OPV) (excluding Polio 0), three injections of diphtheria-pertussis-tetanus (DPT), and one dose of measles before first birthday was considered fully immunized and who had not received even a single dose was considered as non-immunized. Both early and late drop-outs were calculated using Government of India definition. To cross-verify the immunization status, the interviewer verified the date of each received vaccination. If the mother could not show the vaccination card, she was asked if the child had received BCG, DPT, Polio and Measles. While BCG was examined in terms of the scar on the child's arms, information about DPT and Polio was obtained on the basis of the mother's response in terms of number of actual doses of immunization the child had received.

\section{Results}

Results are reflected in sample characteristic measures, status of vaccination against antigens and bivariate analysis for factors affecting vaccination.

The study found that majority of the people residing there were daily labourers, mechanics, rickshaw-pullers, auto drivers and small shop owners. Out of the total 79 children examined, $56 \%$ were males and $44 \%$ females. Among Hindus ( $n=45), 80 \%$ were schedule caste and $20 \%$ of general caste. In terms of literacy level of respondents, $20 \%$ were illiterates, $28 \%$ had up to primary education and $42 \%$ up to secondary level education. Eighty-seven percent mothers were housewives, $9 \%$ were daily labourers and $4 \%$ were into miscellaneous profession. It was found that $65 \%$ of children were completely immunized, $33 \%$ were partially immunized and $2 \%$ were not immunized at all (Figure 1).

Ninety five percent respondents considered vaccination as important for their children (Table 1). When asked about the basic reason behind the importance they attach to vaccination, $81 \%$ respondents attributed this to self-

Table 1. Importance and reasons of immunization status.

\begin{tabular}{lcc}
\hline Attributes & Frequency & $\%$ \\
& n & \\
Vaccination considered as important for child survival & 75 & 94.9 \\
$\quad$ Yes & 1 & 1.3 \\
No & 3 & 3.8 \\
Cannot say & & \\
Basic reasons behind laying importance* & 64 & 81 \\
Self-belief & 5 & 6.3 \\
Influence of neighbors & 18 & 22.8 \\
Health workers' communication & 18 & 22.8 \\
Message aired in electronic media & & \\
\hline
\end{tabular}

*Multiple responses were ticked. Categories are mutually not exclusive.

Table 2. Perception on key indicators of immunization services.

\begin{tabular}{|c|c|c|c|}
\hline Perception on health services & $\begin{array}{l}\text { Yes } \\
(\%)\end{array}$ & $\begin{array}{l}\text { No } \\
(\%)\end{array}$ & $\begin{array}{c}\text { Cannot say } \\
(\%)\end{array}$ \\
\hline $\begin{array}{l}\text { Has it ever happened that you had come for vaccination } \\
\text { and found the service not available? }\end{array}$ & $4(5.1 \%)$ & $74(93.7 \%)$ & 0 \\
\hline $\begin{array}{l}\text { Would you come back to same facility for vaccinating } \\
\text { your child again? }\end{array}$ & $76(96.2 \%)$ & $3(3.8 \%)$ & 0 \\
\hline $\begin{array}{l}\text { Would you come back for vaccinating your child again } \\
\text { if you have option to get the same services from some } \\
\text { other public health facility? }\end{array}$ & $77(97.5 \%)$ & $2(2.5 \%)$ & 0 \\
\hline $\begin{array}{l}\text { Would you come back for vaccinating your child again } \\
\text { if you have option to get the same services from } \\
\text { other private health facility? }\end{array}$ & $6(7.6 \%)$ & $70(88.6 \%)$ & $3(3.8 \%)$ \\
\hline $\begin{array}{l}\text { Do you think not getting vaccine on a prescheduled } \\
\text { date is bad for your child's vaccination continuity? }\end{array}$ & $69(87.3 \%)$ & 0 & $10(12.7 \%)$ \\
\hline $\begin{array}{l}\text { Do you know any of your neighbors who after having } \\
\text { similar experience did not visit the health facility } \\
\text { for further vaccination of his/her children? }\end{array}$ & $\begin{array}{c}1 \\
(1.2 \%)\end{array}$ & $\begin{array}{c}73 \\
(92.4 \%)\end{array}$ & $\begin{array}{c}5 \\
(6.4 \%)\end{array}$ \\
\hline
\end{tabular}

belief, followed by influence of electronic media and communication of health workers (22.8\%, each). With respect to immunization coverage by antigens, BCG coverage was the highest $96 \%$ whereas Measles was $65 \%$. Dropout rate between BCG-Measles, DPT3Measles and DPT1-DPT3 was found to be 30, 27 and $3.94 \%$, respectively. With regard to the distance factor from the service delivery site, it was found that $63 \%$ respondents lived within a distance of one $\mathrm{km}$ from the nearest health centre, while $35 \%$ lived within $1-2 \mathrm{kms}$ and rest $2 \%$ were living at a distance of beyond $2 \mathrm{kms}$. Eighty-five percent respondents attended

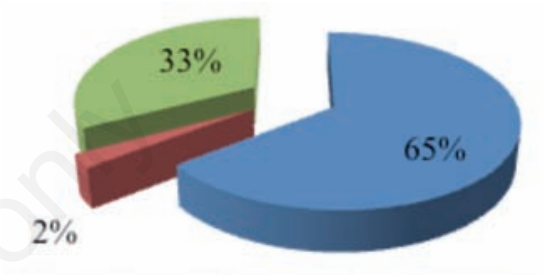

Figure 1. Immunization status. 
health centres by walking and 15\% travelled with their personal vehicles. $93.7 \%$ respondents said that services were available when they visited public health facility (Table 2). Ninety-five percent respondents preferred to take services from public health facility. However, about $7.6 \%$ respondents had also visited private health facilities, and $87.3 \%$ considered getting immunization at right time was important for their child.

As Table 3 indicates, interestingly we found that $75 \%$ respondents' children had adverse events following immunization (AEFI). However, when asked to enumerate the symptoms most respondents mentioned mild fever, loose motion, crying and sleeplessness. With respect to the amount of time they had to spend to avail the services, $77 \%$ mothers waited for less than an hour to immunize their children. When asked as to whether the child was taken for immunization during illness, about $60 \%$ mothers responded negatively. On the other hand, more than $60 \%$ respondents also mentioned that their children were denied immunization services by providers due to illnesses. Among illiterate mothers $(n=16)$, seven children (43.75\%) were completely immunized, while amongst mothers having education level ranging from class one to graduation ( $n=63), 44$ children $(70 \%)$ were fully immunized. On a Likert's five-point scale to rank the importance of immunization services, where 5 meant very important and 1 meant not at all important, we found that behavior of providers, AEFI, regular session, distance, health education by auxiliary nurse midwives, waiting time and loss of wages were ranked as most important in descending order (Table 4). However, interestingly, more than $90 \%$ mothers were satisfied with the services provided at the public health facility. This could be indicative of low-level of expectation among slum-dwellers from public health delivery system and lower level of understanding about quality of services. Mothers during in-depth interview cited frequent illnesses (Figure 2) of the child, lack of information regarding the immunization schedule, frequent displacement of families for economic reasons, poor importance to the impeding diseases, insufficient family members to take the child to immunization site, service providers not attending even mild illnesses, poor knowledge regarding the benefit of immunization and limited but prominent AEFI as the main factors behind late dropouts.

An attempt was made to analyze at what stage the children dropped out and did not get all vaccines. The BCG to Measles dropout rate was found to be the highest $(30 \%)$ in our study, followed by DPT3 to Measles (27\%). Thus, in order to achieve universal immunization goals it is important to track all chil-
Table 3. Perceived factors of immunization coverage.

\begin{tabular}{|c|c|c|}
\hline \multirow[t]{2}{*}{ Attributes } & \multicolumn{2}{|c|}{ Frequency } \\
\hline & n & $\%$ \\
\hline \multicolumn{3}{|l|}{ AEFI } \\
\hline Yes & 60 & 75.9 \\
\hline No & 16 & 20.3 \\
\hline Cannot say & 1 & 1.3 \\
\hline No response & 2 & 2.5 \\
\hline \multicolumn{3}{|c|}{ Time taken for the child to get immunized (h) } \\
\hline$<1$ & 61 & 77.2 \\
\hline $1-2$ & 15 & 19.0 \\
\hline No response & 3 & 3.8 \\
\hline \multicolumn{3}{|c|}{ Had you ever taken your child for immunization when he/she was not well (sick)? } \\
\hline Yes & 31 & 39.2 \\
\hline No & 47 & 59.5 \\
\hline No response & 1 & 1.3 \\
\hline \multicolumn{3}{|c|}{ Did your child receive immunization during that illness episode* $(n=31) ?$} \\
\hline Yes & 12 & 38.7 \\
\hline No & 19 & 61.3 \\
\hline
\end{tabular}

AEFI, adverse events following immunization. * Only for those respondents who had answered yes to the previous question.

Table 4. Ranking of factors for quality immunization services.

\begin{tabular}{|c|c|c|c|c|c|c|}
\hline \multirow[t]{2}{*}{ Attributes } & \multicolumn{5}{|c|}{ Scores* } & \multirow[t]{2}{*}{ Mean score } \\
\hline & 5 & 4 & 3 & 2 & 1 & \\
\hline Behavior of providers & 36 & 40 & 1 & 0 & 0 & 4.45 \\
\hline Adverse effects of immunization & 12 & 59 & 4 & 0 & 0 & 4.10 \\
\hline Regular outreach sessions & 13 & 58 & 5 & 0 & 1 & 4.06 \\
\hline Distance of session site & 2 & 67 & 4 & 1 & 1 & 4.04 \\
\hline Health education by health worker & 6 & 66 & 4 & 0 & 1 & 3.98 \\
\hline Availability of vaccines all the time & 9 & 47 & 21 & 0 & 0 & 3.88 \\
\hline Waiting time & 5 & 45 & 7 & 19 & 0 & 3.47 \\
\hline Health education by doctor & 3 & 14 & 56 & 1 & 0 & 3.28 \\
\hline Loss of daily wages & 4 & 6 & 10 & 51 & 5 & 2.38 \\
\hline
\end{tabular}

*5, very important; 4 , important; 3 , cannot say; 2 , not important; 1 , not at all important.

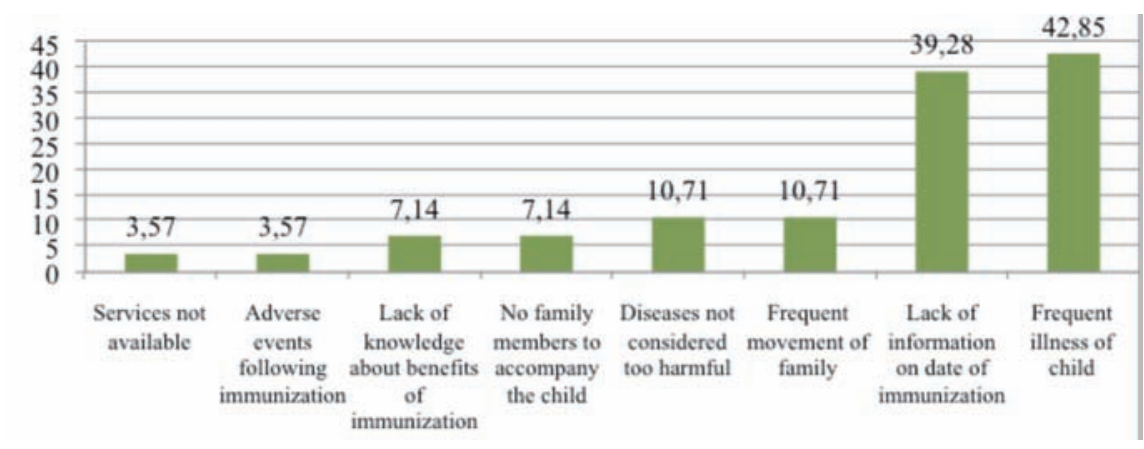

Figure 2. Reasons behind partial or non-immunization (multiple responses were allowed; values are expressed as percentage). 
dren on regular basis. The study also revealed that about $2.5 \%$ children did not receive even a single antigen and were completely left out of the UIP. Comparable figure as reported by Coverage Evaluation Survey (CES) 2009 reported it at $5.2 \%$. We cross-analyzed immunization status with level of education of mothers, and found that though there was no linear association between these two, the coverage of immunization varied according to the educational status of the mother.

\section{Discussion}

Rapid urbanization also is accompanied by proportionate growth of urban slums. ${ }^{12}$ Studies of early $20^{\text {th }}$ century mainly focused on exploring the link between poverty and ill health. ${ }^{13-15}$ Subsequent studies found poor environmental conditions and high population density in urban areas act as precipitating factors behind frequent outbreaks of VPDs. Despite the supposed proximity of the urban poor to health facilities, their access to healthcare is significantly curtailed. This is on account of inadequate public health delivery system, ineffective outreach and weak referral system. The social exclusion and lack of information and assistance at the secondary and tertiary hospitals makes slum dwellers unfamiliar to the modern environment of hospitals and restricts their access. On the other hand, limited purchasing power deters them from accessing private facilities. Lack of benchmark for the health delivery system, when contrasted with the rural network, makes the urban poor even more vulnerable and worse off than his rural counterpart. ${ }^{16-18}$

Demographic projections indicate by 2021 the urban population of the country will increase to 432 million and of slum population to more than 85 million. ${ }^{19,20}$ Undoubtedly, it will exert tiresome strain on the health infrastructure, especially of larger towns and cities that already have serious deficiencies. Lack of preparation to foresee this will limit the options to town planners, public health departments and policy makers, then. Until late 1990 s the urban health centers were grossly inadequate with only one UHP per 145,854 population. ${ }^{21}$ Though the India Population Project-VIII (IPP-VIII, 1993 to 2002) created and upgraded more than one thousand facilities in Karnataka, Delhi, West Bengal and Andhra Pradesh, ${ }^{22}$ it did not include smaller cities and towns across the country. Secondly, there is complete disproportionate staffing for areas against the growth. ${ }^{23}$ And low staff motivation owing to lack of supportive supervision, poor transport facilities often result in weak outreach. ${ }^{24}$ The relatively new Indian Public Health Standards has recommended minimum standards for facilities at various levels, but compliance is far from satisfactory.

Various reasons may explain the lower levels of full immunization coverage in urban slums in India. There are several challenges that are unique to areas, such as, rapid population growth particularly in slum populations, array of types of service providers in both private and public sectors, over-crowding, poor environmental conditions and deterioration of family fabrics. These would need creative strategies to reach the marginal sub-populations. $^{25-27}$ Studies in Nigeria, India and Pakistan indentified factors, such as lack of confidence of health workers in administering vaccines, irregular supply of vaccines, unwillingness of health workers to open vaccine vials until many clients appear at the immunization site, and long interval between sessions as the main reasons for low immunization coverage in urban areas and slum areas. ${ }^{28-33}$ Some of these studies also revealed the extent of missed opportunities for vaccination in the slum settlements. ${ }^{31,33}$

The national complete immunization estimation is $62.5 \%$ for urban areas and $50 \%$ for rural areas. The immunization coverage in Odisha among 12-24 months aged group children is estimated at $94.2,73.9,78.6$ and $81 \%$ for BCG, DPT3, OPV3 and Measles, respectively, while complete/full immunization is estimated at 62.3 against $54 \%$ for India District Level Household and Facility Survey-3 (DLHS3 ). There is no national level or state-specific survey data to assess the urban-rural divide or within urban areas, slum-non-slum divide. Our study found complete immunization at $64.6 \%$ in the slum area of Cuttack. Furthermore, antigen-wise coverage for BCG (96.2\%), DPT3 (92.4\%), OPV3 (92.4\%) and Measles (65.8\%) reflects high instances of late dropouts. Our findings on early and late drop-outs are similar to other studies conducted. ${ }^{27-29}$ The higher coverage of DPT3 and OPV3 could be mainly due to the recent improvement in immunization strategy during 2007-2012 which focused on micro-planning, capacity building, community mobilization and incentivized supervision. However the low coverage of measles vaccine continues to pose serious challenges to the national immunization goals which must be remedied urgently. ${ }^{33}$ Other studies have shown that maternal education, attendance for antenatal and postnatal care, and parity are associated with full vaccination among children. ${ }^{34}$ In rural areas, efficient tracking mechanisms are being followed mainly because of existence of a definite health care delivery system and availability of trained and devoted female health workers. The addition of a volunteering cadre named Accredited Social Health Activists into the health system under National Rural Health Mission has given the impetus to immunization programme for rural residents.
On the contrary, for urban areas, particularly for slum dwellers, there are no link workers to track the partially immunized or unimmunized children. Co-ordination among the multitude of providers, timely and regular outreach, effective monitoring and quality services are critical for improving utilization of immunization services in urban set-ups which have the inherent characteristic of heterogeneity.

The concept of urban advantage seemingly has lost its significance for the poor. The WHO puts it thus: whenever and wherever infrastructure and services are lacking, urban settlements are amongst the world's most life threatening environments. ${ }^{35}$ Disintegration of social fabric in urban areas in general and urban slums in particular has led to erosion of confidence and interpersonal communication among slum dwellers.$^{36}$ From demand side, it is already well established that working mothers do not get adequate family support to attend to child's health needs, as they remain engaged in earning livelihood. From supply side, improper microplanning, underestimated indenting and consequent insufficient supply of vaccines continue to pose challenges to quality immunization for slum areas. ${ }^{37,38}$ Furthermore, the harm caused by poor injection safety and waste disposal outweighs the benefits of vaccination. . $^{39,40}$

Some recommendations on how to bridge the gap between the community and the urban health care delivery system are here provided: i) strengthen the health system: a separate cadre of health functionaries may be created for urban areas, focusing on urban slums. The initiatives under national urban health mission may be expedited to cover the high risk urban pockets on top priority. Unique tracking system can and should be developed to address the issue of frequent displacement of families. ii) Develop local ownership: renewed interest should be developed both in local health functionaries and beneficiaries to accelerate the optimization of immunization services. The role of local municipality may be clearly defined to address the multi-factorial causes of non-immunization or partial immunization. iii) Expand the basket of services: the basket of immunization services may be broadened, such as, family planning counselling, iron, folic acid and vitamin-A supplementation, and provision of iodized salt, to attract and retain parents' attention during the contact period between DPT3 and measles vaccinations. It could also improve the health status of both the mother and the child under life cycle approach. iv) Revisit the urban immunization strategy: the Reproductive and Child Health (RCH) program for immunization should revise its strategy and focus on bottlenecks by reducing the late dropout and improving coverage of measles. Improvement of interpersonal communication with the community would 
increase awareness about sessions and ensure their involvement in service provision for its long-term sustenance. Improved vigilance at session site and supportive supervision by higher officials could improve the level of motivation of service providers. All missed opportunities must be overcome with adequate training, periodic sensitization and regular review. It is high time that we create a dedicated work force for urban areas. Slum volunteering scheme (SVS) or urban social health activist (USHA) may be introduced on priority which would provide the much needed connection in the chain of events for successful immunization of all children. v) Capitalize on the opportunities: municipality health department, civil society organizations, ICDS workers and panchyat raj institution (PRI) members have critical roles to play in counselling, mobilizing, monitoring and linkage establishing activities, respectively. Slum dwellers and health provider linkage must also be strengthened. A multistakeholder co-ordination approach may be adopted as had been done successfully in early 1990s (Universal Immunization Campaign in Kolkata). ${ }^{41}$ vi) Generate more evidence: urban slums are high risk areas leading to high rate of disease transmission. ${ }^{42,43}$ Maternal and child health indicators among slum people show that their health is two to three times worse than non-slum areas. Thus, further studies focusing on the effect of on-site corrective measures and mobilization strategies may be undertaken on time-bound manner.

\section{Conclusions}

Improve access to and utilization of immunization services is low in the urban slums owing to its unique inherent characteristics of urban slums, such as, floating population, overcrowding, poor sanitation and personal hygiene. Urban slums do have more morbidity withholding vaccinations by paramedics; there were also many instances of non-immunization of children because there was no one in the family to take the child to the health centre for vaccination. The traditional temporary migration of pregnant women for delivery, and the consequent non-availability of their records, results in missing out on services at either of the residences. This highlights the need and importance of ensuring immunization for all vulnerable poor. These findings could be helpful to the people in charge of immunization at local level. Anganwadi workers are responsible for identifying and tracking all eligible children for immunization along with the female health workers. Thus, co-ordination between the ICDS under the Department of Women and Child Development and the Department of Health and Family
Welfare at all levels will be crucial in bridging the gap between the community and the urban health care delivery system.

The national UIP goals pose stiff challenges and require to address weak primary health infrastructure, hidden urban poor population, poor social access, inadequate demand for services, week monitoring and policy revision issues. Needless to say then, that there is an urgent need for formulating and implementing a comprehensive urban health policy, focusing on immunization services. If health in all policies is the destination, healthy public policy could be a good beginning.

\section{References}

1. Anderson RM. The concept of herd immunity and the design of immunity-based immunization programmes. Vaccine 1992;10:928-35.

2. WHO. Global Immunization data. Geneva: World Health Organization ed.; 2008. Available from: www.who.int/immunization/newsroom/Global_Immunization_Dat a.pdf

3. Government of India. National commission on population. National population policy. New Delhi: Government of India ed.; 2000.

4. Banthia J. Final population totals, agglomerations and towns. New Delhi: Census of India ed.; 2001.

5. EHP-USAID. Standard of living index based reanalysis of National Family Health Survey (NFHS-2), India and State reports 1998-1999, International Institute for Population Sciences (IIPS) and ORCMacro (2001). Mumbai: EHP-USAID ed.; 2003.

6. Government of India. Coverage evaluation Survey 2009. New Delhi: Government of India, Ministry of Health and Family Welfare ed.; 2009.

7. WHO/UNICEF. Review of national immunization coverage 1980-2002 (India). New Delhi: WHO/UNICEF; 2003.

8. Government of Odisha. The Orissa Gazette. Available from: http://orissa. gov.in/govtpress/pdf/2011/442.pdf

9. Government of India. National Family Health Survey, India. New Delhi: Government of India, International Institute of Population Sciences ed.; 2007. Available from: http://www.rchiips.org/ NFHS/chapters.shtml

10. Cuttack Municipal Corporation. Available from: http://www.cmccuttack.gov.in/ (S(h0gr0mb5yizl2feoe0ttgs3l))/vision.htm l

11. Government of Odisha. Records of ICDS, office of district social welfare officer,
Cuttack. Bhubaneswar: Government of Odisha, Department of Women and Child Development, ed.; 2012.

12. Madhiwalla N. Healthcare in urban slums in India. Natl Med J India 2007;20:113-4.

13. Chandavarkar R. The origins of industrial capitalism in India. Business strategies and the working class in Bombay, 19001940. Cambridge: Cambridge University Press; 1994.

14. Jhirad J. Report on an investigation into the causes of maternal mortality in the city of Bombay. New Delhi: Government of India Press; 1941.

15. Women's Medical Service Organization. Summary of the findings of investigations into the causes of maternal mortality in India. New Delhi, Women's Medical Service Organization ed.; 1947.

16. Agarwal S, Bhanot A, Goindi G. Understanding and addressing childhood immunization coverage in urban slums. Indian Pediatr 2005;42:653-63.

17. Lodha R, Dash N, Kapil A, Kabra S. Diphtheria in urban slums in north India. Lancet 2000;355:204.

18. Loening W, Coovadia H. Age specific occurrence rates of measles in peri-urban, and rural environment: implications for time of vaccination. Lancet 1983;2:324-6.

19. Government of India. Provisional population tables. Registrar general and census commissioner. New Delhi: Ministry of Home Affairs, Government of India ed.; 2011.

20. Government of India. Report of the committee on slum statistics/census 2010. New Delhi: Ministry of Housing and Urban Poverty Allevation, Government of India ed.; 2010. Available from: http://mhupa.gov.in/W_new/Slum_Report_ NB0.pdf

21. Government of India. Annual report on special schemes, 1999-2000. New Delhi: Government of India, Ministry of Health and Family Welfare ed.; 2000.

22. Institute for Research in Medical Statistics. India population project-VIII. End-line survey, 2003. New Delhi: Institute for Research in Medical Statistics ed.; 2003.

23. Lal S, Vashisht BM. Innovative approaches to universalize immunization in rural areas. Indian J Community Med 2003;28: 51-6.

24. Darshana V, Ramesh K. Immunization promotion in Ahmedabad. Paper presented at the Health Consultation organized by Environment Health Project and Ministry of Health and Family Welfare, 2003 June 30-July 1, Bangalore, India. New Delhi: Ministry of Health and Family Welfare, Government of India ed.; 2003.

25. Atkinson SJ, Cheyne J. Immunization in 
urban areas: issues and strategies. B World Health Organ 1994,72:183-94.

26. Mutua MK, Kimani-Murage E, Ettarh RR. Childhood vaccination in informal urban settlements in Nairobi, Kenya: who gets vaccinated? BMC Public Health 2011;11:6.

27. Sharma R, Desai VK, Kavishvar A. Assessment of immunization status in the urban slums of surat by 15 clusters multi indicators cluster survey technique. Indian J Community Med 2009;34:152-5.

28. Odusanya 0, Alufohai E, Meurice F, Ahonkhai V. Determinants of vaccination coverage in rural Nigeria. BMC Pubic Health 2008;8:381.

29. Chhabra P, Nair P, Gupta A, et al. Immunization in urbanized villages of Delhi. Indian J Pediatr 2007;74:131-4.

30. Torun S, Bakirci N. Vaccination coverage and reasons for non-vaccination in a district of Istanbul. BMC Public Health 2006;6:125.

31. Agarwal S, Bhanot A, Goindi G. Understanding and addressing childhood immunization coverage in urban slums. Indian Pediatr 2005;42:653-63.
32. Odiit A, Amuge B. Comparison of vaccination status of children born in health units of those born at home. E Afr Med J 2003;80:3-6.

33. Nath B, Singh J, Awasthi S, et al. A study on determinants of immunization coverage among 12-23 months old children in urban slums of Lucknow district, India. Indian J Med Sci 2007;61:598-606.

34. Rahman M, Obaida-Nasrin S. Factors affecting acceptance of complete immunization coverage of children under five years in rural Bangladesh. Salud Publica Mex 2010;52:134-40.

35. Satterthwaite D. The Earthscan reader on sustainable cities. London: Earthscan Publ.; 1999.

36. Egolf B, Lasker J, Wolf S, Potvin L. The Roseto effect: a 50-year comparison of mortality rates. Am J Public Health 1992;82:1089-109.

37. Kaur M, Reddaiah V, Kant S. Primary immunization status of children in slum areas of South Delhi: the challenge of reaching the urban poor. Indian $\mathrm{J}$ Community Med 2001;26:151-4.
38. Hutchins S, Jansen H, Robertson S, et al. Studies of missed opportunities for immunization in developing and industrialized countries. B World Health Organ 1993;71:549-60.

39. Brown P. India: an environmentally sustainable solution in a crowded country. Geneva: GAVI ed.; 2002.

40. Hunt C. Child waste pickers in India: the occupation and its health risks. Environ Urban 1996;8:111-8.

41. Chaudhuri ER. Universal immunization in urban areas: Calcutta's success story. Indian J Public Health 1990;34:227-34.

42. Government of India. Draft final report of the task force to advise the national rural health mission on "Strategies for Health Care". New Delhi: Ministry of Health and Family Welfare, Government of India ed.; 2006.

43. Government of India. Guidelines for developing city level health projects. New Delhi: Ministry of Health and Family Welfare, Government of India ed.; 2004. 